\title{
5. Curar Algumas Vezes, Aliviar Quase Sempre, Consolar Sempre
}

\author{
Joffre Marcondes de Rezende
}

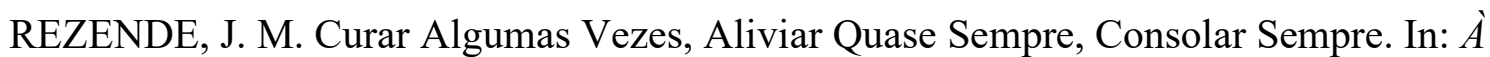
sombra do plátano: crônicas de história da medicina [online]. São Paulo: Editora Unifesp, 2009, pp. 55-59. História da Medicina series, vol. 2. ISBN 978-85-61673-63-5. https://doi.org/10.7476/9788561673635.0006.

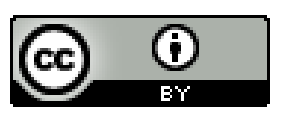

All the contents of this work, except where otherwise noted, is licensed under a Creative Commons Attribution 4.0 International license.

Todo o conteúdo deste trabalho, exceto quando houver ressalva, é publicado sob a licença Creative Commons Atribição 4.0.

Todo el contenido de esta obra, excepto donde se indique lo contrario, está bajo licencia de la licencia Creative Commons Reconocimento 4.0. 


\section{Curar Algumas Vezes, Aliviar Quase Sempre, Consolar Sempre*}

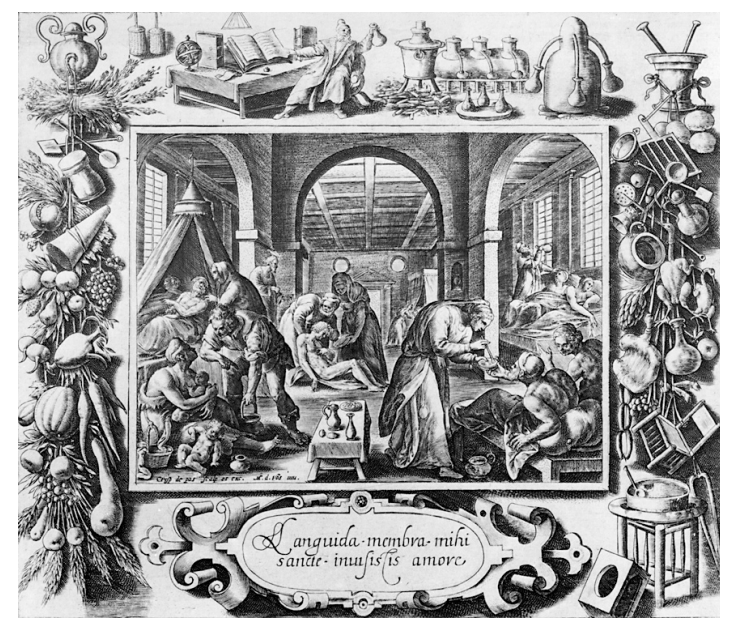

Gravura O Socorro ao Doente, de Crispin de Passe, o Velho (século XVII).

$\mathrm{E}$ ste aforismo define o compromisso do médico para com os doentes e foi consagrado como divisa da própria medicina. É frequentemente atribuído a Hipócrates (Druss, 2003, pp. 25-26; Goldbloom, 2003). Poderia talvez ter sido inspirado na medicina hipocrática, mas não é encontrado nos livros que integram o Corpus Hippocraticum.

Há duas traduções das obras de Hipócrates que são clássicas: a tradução francesa de Littré e a tradução inglesa de Jones.

No livro Peri Tékhne (Da Arte), Hipócrates define a medicina e seu principal objetivo da seguinte maneira:

Quant á la médecine (car c'est d'elle qu'il sagit) j'en vais faire la demonstration; et d'abord la définissant telle que je la conçois, je dit que l'objet en est, en général, d'écarter les souffrances des malades et diminuer la violence des maladies, tout en s'abstenant de toucher à ceux chez qui le mal est le plus fort; cas placé

* Apresentado ao XI Congresso Brasileiro de História da Medicina, Goiânia, I 8-2I out. 2006. 
comme on doit le savoir, au-dessus des ressources de l'art (Hipócrates, I933, p. I90, tradução francesa de Littré).

First I will define what I conceive medicine to be. In general terms, it is to do away with the sufferings of the sick, to lessen the violence of their diseases and to refuse to treat those who are overmastered by their diseases, realizing that in such cases medicina is powerless (Hipócrates, I972, p. I93, trad. inglesa de Jones).

Com base nas versões clássicas de Littré e de Jones o texto poderia ser assim traduzido em português: "Quanto à medicina, tal como eu a concebo, penso que o seu objetivo, em termos gerais, é o de afastar os sofrimentos do doente e diminuir a violência das suas doenças, abstendo-se de tratar os doentes graves para os quais a medicina não dispõe de recursos".

Vemos que a preocupação do autor se concentra em aliviar os sofrimentos do paciente e diminuir a gravidade das doenças. Não foi dada ênfase à cura, que, na época de Hipócrates, como ele mesmo ensinava, dependia primordialmente das forças da natureza (Physis). As doenças seguiam o seu curso natural, tinham seus dias críticos e o papel do médico era "auxiliar a natureza" para obter a cura.

Também não há menção a "consolar"; ao contrário, o médico deveria abster-se de tratar os doentes graves, para os quais a medicina não dispõe de recursos (Hipócrates, I933). No comentário sobre o livro Da Arte, Littré refere-se ao caráter desumano dessa prática. Era uma tradição da medicina grega não acolher no Asklepeion, que era um misto de hospital e templo consagrado a Asclépio, deus da medicina, os doentes terminais ou incuráveis.

É evidente que, não sendo da época de Hipócrates, o referido aforismo é de data posterior. $\mathrm{O}$ apelo ao sentimento piedoso de solidariedade humana como missão adicional do médico nos faz crer na influência do cristianismo. Do mesmo modo que os deuses da mitologia grega foram substituídos por Cristo no juramento de Hipócrates, assim também o médico deveria cuidar dos doentes sem possibilidade de cura (consolar sempre).

Nas referências mais antigas o aforismo data do século xv e está redigido em francês: "Guérir quelquefois, soulager souvent, consoler toujours". Possivelmente a frase em francês já é uma tradução do latim medieval. Há em latim uma sentença semelhante: "medicus quandoque sanat, saepe lenit 
et semper solatium est" ( $\mathrm{O}$ médico às vezes cura, muitas vezes alivia e sempre é um consolo) (Rezende e Silva, I955, p. 402).

Do francês o aforismo foi traduzido para outras línguas. Em inglês: "To cure sometimes, to relieve often, to comfort always"; em italiano: "Guarire qualche volta, alleviare spesso, confortare sempre"; em espanhol: "Curar algunas veces, aliviar frecuentemente y consolar siempre".

Em português, ao contrário do francês e do inglês, a frase tem sido redigida com algumas variações de palavras.

I. Curar algumas vezes, aliviar quase sempre, consolar sempre.

2. Curar algumas vezes, aliviar frequentemente, consolar sempre.

3. Curar algumas vezes, aliviar muitas vezes e consolar sempre.

4. Curar algumas vezes, aliviar outras, consolar sempre.

5. Curar algumas vezes, aliviar frequentemente, confortar sempre.

6. Curar às vezes, aliviar muito frequentemente e confortar sempre.

7. Curar algumas vezes, aliviar outras, cuidar sempre.

8. Curar às vezes, aliviar com frequência, consolar sempre.

9. Curar algumas vezes, aliviar o sofrimento sempre que possível, confortar sempre.

A tradução que mais se aproxima do original francês é a do item 3 : "Curar algumas vezes, aliviar muitas vezes, consolar sempre".

Em alguns artigos veiculados pela imprensa médica e em vários textos que se encontram na internet seus autores atribuem equivocadamente a paternidade desse aforismo a autores de épocas mais recentes, tais como Trudeau, Osler, Holmes, Peabody, Nothnagel, como nos exemplos que se seguem. Dentre todos, Trudeau é o mais citado: "Curar algumas vezes, aliviar outras, cuidar sempre - uma lição secular do dr. Edward Trudeau, que não devemos esquecer" (Neubarth, 2004, pp. 7I-74); "A psicoterapia foge um pouco ao mandamento obrigatório na medicina: 'Curar às vezes, aliviar com frequência, consolar sempre' (Francis Trudeau)" (Edelweiss, s.d.).

Edward Linvingstone Trudeau (I848-I9I5) foi um médico norte-americano que se dedicou ao tratamento da tuberculose e fundou um sanatório para tuberculosos em Saranac Lake, nos Estados Unidos. Ele foi de uma dedicação extrema aos doentes em uma época em que ainda não havia 
tratamento específico para esta enfermidade. Em I9 18, seus ex-pacientes se quotizaram e erigiram, junto ao sanatório, um monumento em sua memória, em cujo pedestal foi gravado o aforismo em francês "Guérir quelquefois, soulager souvent, consoler toujours". As pessoas mal informadas julgam que ele foi o autor da frase.

Outros dão a autoria a Osler, como neste registro: "Com o ressurgimento dos cuidados paliativos volta a fazer sentido a expressão de Osler [...] 'Curar às vezes, aliviar com frequência, consolar sempre'” (Nunes, s.d.). William Osler ( I849-I9I9) foi o maior clínico do século xx, tendo sido um dos fundadores da Faculdade e Hospital Johns Hopkins, em Baltimore, que serviu de modelo para a implantação da moderna medicina norte-americana. Além de docente e pesquisador, Osler destacou-se por sua preocupação com o lado humano da medicina e suas citações do aforismo foram atribuídas à sua própria autoria.

"Curar às vezes, aliviar muito frequentemente e confortar sempre Oliver Holmes” (Siqueira, 2000). Oliver Wendel Holmes ( I 809-I 894), além de médico, foi um apreciado escritor e poeta. Realizou estudos sobre a febre puerperal e sugeriu o nome de anestesia para a descoberta de William Thomas Morton.

"Como já dizia Francis Peabody: to cure sometimes, to relief often and to confort always" (Simplicíssimo, 2003). Francis W. Peabody (I88 I-I927), médico norte-americano, foi um paradigma de dedicação aos pacientes e escreveu um trabalho que se tornou clássico sobre a humanização da medicina, intitulado "The care of patient", publicado em I927.

"O médico tem de curar algumas vezes, aliviar muitas e consolar sempre.É com base nesse ensinamento de Nothnagel, que estudantes do curso de Medicina [...] desenvolvem o Projeto de Vivência na Integração Médico-Paciente, o Provimp" (Madeiro, I998). O nome de Hermann Nothnagel (I84I-I905), médico alemão que viveu de I 84 I a I905, ficou consagrado na Nothnagel's Encyclopedia of Practical Medicine, do início do século xx.

Em conclusão, todas as referências citadas são improcedentes: não se conhece o autor da frase, nem quando a mesma foi usada pela primeira vez. $\mathrm{O}$ citado aforismo aflorou naturalmente como síntese da própria medicina e do compromisso do médico para com a humanidade sofredora. 


\section{Referências Bibliográficas}

Druss, R. G. "Introspections. To Comfort Always”. The American Journal of Psychiatry, I60, jan. 2003.

Edelweiss, M. L. "O Cliente, a Psicoterapia e o seu Contexto”. Disponível em http:// www.malomar.com.br/textos/textoo2a.htm, acesso em I7 dez. 2005.

Goldbloom, D. S. "Language and Metaphor". Bulletin of the Canadian Psychiatric Association, vol. 35 , n. 3 , jun. 2003.

Hipócrates. De l'Art. Hippocrate: Oeuvres complètes. Trad. E. Littré. Paris, Javal et Bourdeaux, I933.

. The art. Hippocrates, vol. II. Trad. W. H. S. Jones. (The Loeb Classical Library.) Cambridge, Havard University Press, I972.

Madeiro, M. "Curar, Aliviar, Consolar Sempre”. Diário do Nordeste, Fortaleza, I6 set. 1998 .

Neubarth, F. “Dor, Quinto Sinal Vital”. Revista Brasileira de Reumatologia, 44, 2004.

Nunes, R. “O Doente Oncológico em Fase Terminal”. Disponível em http://quimioterapia.com.sapo.pt/Atitudes\% 20e\% 20comportamentos.htm, acesso em I7 dez. 2005.

Rezende e Silva, A. V. Phrases e Curiosidades Latinas. $5^{\underline{a}}$ ed. fac-similar, Rio de Janeiro, I955.

Simplicíssimo, n. I 5, Santa Maria/Porto Alegre, 2003.

Siqueira, J. E. "Bioética na Terminalidade da Vida”. Boletim da Sociedade Brasileira de Bioética, ano 2, n. 4, out. 2000 